\title{
Relationships between Parent-Reported Parenting, Child-Perceived Parenting, and Children's Mental Health in Taiwanese Children
}

\author{
Ching-Yu Huang ${ }^{1, * \mathbb{C}}$, Yi-Ping Hsieh ${ }^{2} \mathbb{D}$, April Chiung-Tao Shen ${ }^{3}$, Hsi-Sheng Wei ${ }^{4}$, \\ Jui-Ying Feng ${ }^{5}$, Hsiao-Lin Hwa ${ }^{6}$ and Joyce Yen Feng ${ }^{3}$ \\ 1 Department of Psychology, Bournemouth University, Fern Barrow BH12 5BB, UK \\ 2 Department of Social Work, University of North Dakota, Grand Forks, ND 58202, USA; yiping66@gmail.com \\ 3 Department of Social Work, National Taiwan University, Taipei 106, Taiwan; acshen@ntu.edu.tw (A.C.-T.S.); \\ yencertain@gmail.com (J.Y.F.) \\ 4 Department of Social Work, National Taipei University, New Taipei City 23741, Taiwan; \\ hswei@mail.ntpu.edu.tw \\ 5 Department of Nursing, National Cheng Kung University, Tainan City 701, Taiwan; \\ juiying@mail.ncku.edu.tw \\ 6 Department and Graduate Institute of Forensic Medicine, National Taiwan University, Taipei 100, Taiwan; \\ hwahl013@ntu.edu.tw \\ * Correspondence: soarhuang@gmail.com; Tel.: +44-1202-965-274
}

Received: 7 March 2019; Accepted: 19 March 2019; Published: 23 March 2019

check for updates

\begin{abstract}
The current study examines the relationship between parents' and children's reports of parenting and their effects on children's mental health symptoms. Six hundred and sixty-six parent-child dyads in Taiwan participated in this study. The parents and the children filled out the parenting questionnaires, and the children also reported their general mental health. The results demonstrated that parental-reported and child-perceived parenting were positively correlated, but parents tended to report lower scores on authoritarian parenting and higher scores on Chinese parenting than did their children. There were also significant gender differences: The mothers reported higher authoritative parenting than did the fathers; and the boys perceived higher authoritarian and Chinese-culture specific parenting than did the girls. Moreover, the Chinese parenting had a negative effect on children's mental health outcomes. Finally, our results showed that children's perception of parenting had a stronger effect on children's mental health symptoms than did parental reports on parenting, urging future research to include the children's report when investigating the effects of parenting on children's mental health outcomes.
\end{abstract}

Keywords: parenting; culture; gender differences; child mental health

\section{Introduction}

Parenting affects various aspects of children's psychological health, such as self-esteem [1], emotional regulation [2], socio-emotional adjustment, and well-being [3]. The majority of parenting research have adopted two major approaches: a dimensional approach which focuses on individual dimensions of parental behaviors (such as control/demandingness and warmth/responsiveness) [4], and a categorical approach that categorizes parenting according to a combination of parenting dimensions into parenting styles, such as authoritative, authoritarian, permissive, or neglectful parenting styles [5]. Parental responsiveness/warmth can be characterized by supportive, sensitive, accepting, and nurturing parental behaviors, while parental demandingness/control has been conceptualized as a set of active parental strategies involving the communication of clear and 
consistent expectations for appropriate behavior and efforts to monitor the child's behavior related to these expectations [6]. Using the two parenting dimensions, four parenting styles can be identified: authoritative parenting characterized by high levels of parental warmth as well as control; authoritarian parenting with low levels of parental warmth and high degree of parental control; permissive parenting with high levels of parental warmth yet low levels of parental control, and lastly, neglectful parenting with minimal levels of parental warmth and control. Studies among European American populations have yielded consistent results demonstrating the association between authoritative parenting style and positive child outcomes, including better self-esteem and better mental health $[7,8]$. Close parent-child relationships characterized by warmth and acceptance are often protective against the development of children's depression and conduct problems $[9,10]$. In contrast, harsh parenting practice or the authoritarian parenting style have been associated with increased problem behaviors and depressive symptoms $[10,11]$.

However, parenting styles and beliefs are subjected to social and cultural influences [12-14], and the effects of different parenting styles on children's developmental outcomes also vary across cultural groups [15]. In Chinese and Chinese immigrant populations, similar to their European American counterparts, authoritative parenting has been associated with positive child adjustment [16-18], whereas associations between authoritarian parenting and child outcome has been mixed. Some studies have found that harsh or authoritarian parenting has predictable negative consequences for both European American and Chinese children, including emotion dysregulation [19], aggression [20], lower educational attainment [21], and depressive symptoms [22,23] and children's behavioral deviance $[18,24]$. Conflicting results showed that Chinese children were generally satisfied with their parents' authoritarian parenting, and they perceived their parent-child relationships more positively if their parents were more authoritarian [25]. Therefore, authoritarian parenting may have less negative effects among Chinese children (as opposed to their Euro-American counterparts) because they view parents' attempts to regulate them as an act of love [26]. High parental endorsement of "training", an indigenous Chinese parenting concept dictating parents teaching children early through guidance and monitoring of their behaviors, while providing care, concern, support, and parental involvement [26], has been shown to reduce the correlation between authoritarian parenting and both internalizing and externalizing problems among Chinese-American immigrant children [20], suggesting the discipline-behavior problem link being moderated by cultural context. These findings have led researchers to advocate for a culturally anchored approach to understanding and classifying parenting styles.

Although authoritarian and authoritative parenting styles are both found in Chinese societies $[16,24]$ and immigrant Chinese parents $[17,27]$, some culturally important and specific Chinese parenting concepts cannot be fully captured using parenting typologies constructed in European American cultures [26,28]. For instance, Kim et al. [22] used latent profile analyses on eight parenting dimensions to identify four parenting profiles among Chinese American parents: supportive (high on both parental warmth and positive control), tiger (high on both parental warmth and hostility), easygoing (low on both parental warmth and hostility), and harsh (low on parental warmth and high on negative control) parenting. Their results demonstrated the supportive parenting profile being the most common, and it was associated with the best developmental outcomes. The second most common was the easygoing parenting, followed by tiger parenting and harsh parenting. Tiger parenting was not the most typical parenting profile in Chinese American families, nor did it lead to optimal developmental outcomes among Chinese American adolescents [22]. Moreover, researchers have identified five Chinese-culture specific parenting styles beyond the widely-accepted authoritative and authoritarian parenting styles in Chinese and immigrant Chinese parents: Parental protection, directiveness, shaming, encouragement of modest behavior, and maternal involvement [14].

In Chinese culture, young children are viewed as incapable of understanding and making decisions that are in their own best interests [29]. Therefore, 'parental protection' reflects Chinese parents' expectations of themselves having the responsibility to provide a safe environment for their 
children. Such responsibilities are seen as the primary responsibility of parents of young children [14]. Based on the same assumption that young children are incapable of understanding, 'directiveness' refers to parents taking major responsibility for regulating their children's behavior and academic performance [30]. 'Shaming' is a Chinese socialization practice that helps children learn to be sensitive to the perceptions, feelings, evaluations, and judgments of others in order to teach them to avoid future behaviors that would bring shame or embarrassment to the family [31]. 'Encouragement of modest behavior' refers to encouraging children to behave in a humble and socially conforming way when interacting with others to maintain social and interpersonal harmony, because maintaining such harmony is of prime importance in traditional Chinese society [32]. 'Maternal involvement' describes Chinese mothers' extensive involvement and devotion to their children, particularly during the early years, by providing a very nurturing environment for the children by being physically available and by promptly attending to all their children's needs [14].

These five Chinese parenting constructs were shown to not overlap with and were independent of the authoritative and authoritarian constructs identified in North American research [14]. Chinese mothers reported using more Chinese parenting than their U.S. and U.K. counterparts [14,33]; whereas the Chinese immigrant mothers in the U.S. and the U.K. reported similar level in the Chinese-specific parenting to their non-immigrant counterpart in Taiwan [34]. These findings demonstrated that these Chinese parenting practices are still prevalent in Chinese populations, including Chinese immigrants. Although some of the Chinese cultural-specific parenting values, such as shaming and parental protection, were found to be associated with children's internalizing symptoms [22,35], research examining the effect of Chinese culture-specific parenting on children's mental health remains scarce. Therefore, one of the objectives of the current study is to examine the relationships between different parenting styles, particularly Chinese parenting, and their effects on children's mental health outcome.

Other than the ethnic and cultural issues in this line of research, another methodological constraint in parenting research lies in the source of the parenting reports. Some researchers studied the association between parent and child reports of parenting and found that these were only low to moderately correlated [36,37]. Previous research did find associations between parenting practices and child externalizing behaviors [11] as well as internalizing symptoms [10]; the majority of research in this area relied on parental reports of parenting practices, especially with younger children $[38,39]$. The child's perspective on how their parents affect their emotional and behavioral functioning had been less extensively examined [36], perhaps due to questions concerning the reliability and validity of such reports. Fortunately, increasing research has shown that adolescents can provide reliable and valid reports of parenting and their own emotional and behavioral functioning [8,9,40,41]. Children may be influenced by their perceptions of parental behaviors rather than by actual parental behaviors or those reported by the parents [42]. Indeed, empirical studies demonstrated that conclusions based on parents' reports are quite different from those derived from children's reports on parallel measures [43], and agreements between parental and child reports on parenting practices varied according the aspects of parenting examined [37,44]. Moreover, parents from different socio-cultural contexts may have different behavioral norms as well as parenting expectations, thus it is not surprising to see cultural background as one of the moderating factors affecting the agreements between parental and child reports on parenting [37]. Indeed, past research reported a high level of discrepancy between the parenting practices Chinese American adolescents experience and those reported by their parents [45]. Therefore, including both parents' and children's reports of parenting in examining effects of parenting on child mental health will provide valuable information. Thus, another objective of the current study is to examine the associations between parental reports and children's perception of parenting and compare their effects on children's psychological symptoms.

Previous research has established the important concurrent and long-term influence of parenting on children's development and psychological health. However, the links between parents' and children's reports on parenting, and each of their effect on children's mental health outcomes, had rarely been examined within the same study despite concerns regarding congruences between parental and 
child reports having been evident $[37,43,44]$. Furthermore, research regarding the effect of cultural contexts and culturally-rooted parenting practice alongside the more established authoritative and authoritarian parenting on child mental health was even rarer within such discussions, especially within the Chinese cultural context. Thus, the current study will be the first of its kind in examining both parents' and children's reports on parenting, especially including the Chinese cultural-specific parenting, on children's mental health within the Chinese population. The first objective of the current study is to examine whether the parent and the children report differently on the following three parenting styles: authoritative, authoritarian, and Chinese parenting, which are situated at a similar level psychometrically. The second objective is to compare the effects of parental reported parenting and child-reported parenting on children's psychological symptoms. We aim to answer the following questions: (1) Do parents' reports of parenting differ from the children's perception of parenting? If so, how do they relate to one another in each parenting dimension? (2) Does children's perception of parenting account for more variance than does parental reported parenting in children's psychological symptoms? Based on previous research findings, we hypothesized that there will be significant differences between parental and children's reports on each parenting dimension, particularly with parents reporting higher levels of authoritative parenting than their children. We also hypothesized that children's perception of parenting will explain more variance in children's psychological symptoms than will parental reports of parenting.

\section{Materials and Methods}

\subsection{Participants and Procedure}

The participants were 666 fourth-grade (mean age $=10.4$ years, $\mathrm{SD}=0.50$, range $=9.2$ to 10.8) Taiwanese students, with 310 boys (46.5\%) and 356 girls (53.5\%), and their parents (mean age $=39.7$ years, $\mathrm{SD}=5.38$, with $180(27 \%)$ fathers and $486(73 \%)$ mothers). Most $(580,87 \%)$ of the parents were married or cohabitating; some parents were divorced/separated $(73,11 \%)$ or in single-parenthood $(13,2 \%)$. The monthly income of these families (measured by self-report) ranged from less than 1333 USD/month (245, 36.8\%), between 1334 and 2665 USD/month (259, 38.9\%), to over 2666 USD/month $(154,23.1 \%)$. Eight $(1.2 \%)$ of the families refused to answer the question regarding monthly family income. Eighty-eight (13.2\%) of the parents obtained 12 years or less formal education, $442(66.3 \%)$ had vocational or high school diploma, and 136 (20.4\%) held a bachelor or graduate degree.

This project was the pilot study of a larger research project approved by the National Taiwan University Hospital Institutional Review Board (approval code 201305042RINB). In addition to the formal project IRB approval, this pilot study was reviewed and approved by the advisory board committee members of the National Taiwan University Children and Family Research Center. After gaining ethical approval, we first stratified the sample by geographical locations (i.e., 6 counties or cities in northern, southern, and central Taiwan) before we randomly selected primary schools in each county or city for recruitment. Trained research assistants contacted the selected schools' principals for recruitment. The consenting schools distributed both a cover letter and an informed consent form to the parents of the 4 th-grade (10 years old) students. The cover letter and consent form clearly explained the objectives of the research project, emphasizing the voluntary nature of the study, and the contact details of the research team were also given. Once the parents consented to participate, they received the parenting questionnaires to complete before the data collection. Only $17.3 \%$ of the parents of the participating schools agreed to participate, and the parents self-identified as the primary caregiving parent of the child. Due to constraints of resources and time, we were only able to include the primary caregiving parents for participation in the study. Their children then brought the signed informed consent forms and questionnaires in sealed envelopes back to the classroom where the research assistants retrieved them on the day of the data collection for the children. Nearly all (99.9\%) of the children of the consented parents agreed to participate. Before letting the students sign the informed consent forms, our research assistants explained the study's purpose and procedures to students, 
emphasizing the voluntary and anonymous nature of the research. Then, the research assistants distributed self-report questionnaires to consenting students in group sessions at the time agreed with the schools, either during or outside of regular class hours. After completing the questionnaires, the participating students received a set of stationery, and participating parents received 100 TWD (equivalent of 3.3 USD) gift voucher as a token of our thanks.

\subsection{Measures}

Parenting. Parents reported their parenting styles using the Parenting Styles and Dimensions Questionnaire (PSDQ) $[14,46]$. We used the version from $\mathrm{Wu}$ et al., as this version had already been validated in the Chinese population [14]. The questionnaire covers 3 parenting subscales: the authoritative parenting ( 15 items, such as, "I give praise when my child is good" and "I give comfort and understanding when my child is upset"), the authoritarian parenting (11 items, example items included "I yell or shout when my child misbehaves" and "I spank when my child is disobedient"), the Chinese-specific parenting (18 items, for instance "I overly worry about my child getting hurt" and "I tell my child that I get embarrassed when he/she does not meet my expectations"). Wu et al. [14] had excluded the permissive subscale from the original PSDQ questionnaire because it could not be measured reliably in Chinese samples. All items were rated on a 5-point scale ranging from 1 (never) to 5 (always). Mean scores of each subscale were used for subsequent statistical analyses. The internal consistency of the parenting questionnaire (Cronbach's $\alpha$ ) demonstrated high internal consistency for each subscale ( $\alpha=0.919$ for authoritative parenting subscale, $\alpha=0.870$ for authoritarian parenting subscale, and $\alpha=0.757$ for Chinese parenting subscale).

Perceived parenting. We adapted the questionnaire items from $\mathrm{Wu}$ et al. [14]'s version of Parenting Styles and Dimensions Questionnaire $[14,46]$ for it to be appropriate for the child participants. The questionnaire's subscales cover 3 perceived parenting styles: the authoritative parenting (4 items, such as, "My parents give praise when I am good" and "My parents give comfort and understanding when I am upset"), the authoritarian parenting ( 3 items, example items included "My parents yell or shout at me when I misbehave" and "My parents spank me when I am disobedient"), and the Chinese-specific parenting ( 3 items, for example, "My parents overly worry about me getting hurt" and "My parents tell me that they get embarrassed when I do not meet their expectations"). The questionnaire was modified in order to measure the same parenting constructs as the original PSDQ whilst shortened significantly in order to fit the child population. Items were selected based on their factor loading, so only the highest loading items were chosen for each dimension. All items were rated on a 5-point scale anchored by 1 (never) and 5 (always). Mean scores of each dimension were used for subsequent statistical analyses. The perceived parenting questionnaire also demonstrated high internal consistency (Cronbach's $\alpha=0.839$ for perceived authoritative parenting subscale, 0.746 for perceived authoritarian parenting subscale, 0.574 for perceived Chinese parenting subscale). In order to ensure the validity of the perceived parenting scale, a Confirmatory Factor Analysis with varimax rotation was conducted, and the results confirmed that the three-factor structure (authoritative, authoritarian, and Chinese parenting) was maintained for the perceived parenting scale (see Table 1). The estimated model chi-square was $\chi^{2}(18, N=666)=52.962, p<0.001$. The Comparative Fit Index (CFI) was 0.946; the Tucker-Lewis Fit Index (TLI) was 0.972, and the RMSEA was 0.054 (with confidence interval between 0.046 and 0.061), demonstrating acceptable fit for the model.

The Brief Symptom Rating Scale (BSRS-5). The Brief Symptom Rating Scale (BSRS-5) [47] is composed of 5 self-report items by which participating children can evaluate their psychological symptoms in the past week. The BSRS-5 is commonly used in Taiwan for screening psychological disorders and has been shown to significantly predict healthy participants' quality of life, demonstrating empirical support for external validity [48]. It measures anxiety (e.g., "I felt tense or high-strung"), hostility (e.g., "I felt easily annoyed or irritated"), depression (e.g., "I felt depressed or in a low mood"), interpersonal sensitivity (e.g., "I felt inferior to others"), and additional symptoms (e.g., "I had trouble falling asleep"). The score for each item ranges from 0 to 4 ( $0=$ not at all, $1=\mathrm{a}$ 
little bit, 2 = moderately, 3 = quite a bit, and $4=$ extremely), and the sum score of these five items were used in the subsequent analyses. The internal consistency of the BSRS-5 (Cronbach's $\alpha$ ) was 0.876, demonstrating high internal consistency. A sum score of the BSRS-5 above 14, or a score of more than 1 on the additional suicide survey item, may indicate a severe mood disorder. Scores between 10 and 14 may indicate moderate mood disorders, and those between 6 and 9 could indicate mild mood disorders [48]. The participants with BSRS- 5 scores lower than 5 were considered to be normal [47].

Table 1. Factor loadings with varimax rotation of each item in the perceived parenting scale.

\begin{tabular}{|c|c|c|c|}
\hline Perceived Parenting Scale Items & $\begin{array}{c}\text { Factor } 1 \\
\text { Authoritative }\end{array}$ & $\begin{array}{c}\text { Factor } 2 \\
\text { Authoritarian }\end{array}$ & $\begin{array}{l}\text { Factor } 3 \\
\text { Chinese }\end{array}$ \\
\hline My parents give praise when I am good & 0.829 & -0.031 & -0.046 \\
\hline My parents give comfort and understanding when I am upset & 0.841 & -0.169 & -0.017 \\
\hline My parents encourage me to talk about my troubles with them & 0.797 & -0.093 & 0.071 \\
\hline My parents explain and discuss the consequences of my behavior with me & 0.774 & -0.028 & 0.109 \\
\hline My parents spank me when I am disobedient & -0.043 & 0.821 & 0.070 \\
\hline My parents slap me when I misbehave & -0.051 & 0.777 & 0.090 \\
\hline My parents yell or shout at me when I misbehave & -0.158 & 0.769 & 0.136 \\
\hline My parents overly worry about me getting hurt & 0.341 & -0.182 & 0.598 \\
\hline My parents tell me that they get embarrassed when I do not meet their expectations & -0.104 & 0.352 & 0.625 \\
\hline My parents make me feel guilty when I do not meet their expectations & -0.045 & 0.254 & 0.793 \\
\hline
\end{tabular}

Note: Factor loading greater than 0.400 were highlighted in bold.

\subsection{Statistical Analyses}

We used SPSS version 23 for data analyses. First, descriptive statistics were used to assess the distribution of parent-reported parenting, child-perceived parenting, and mental health. Second, we conducted correlational analyses to illustrate interrelationships between each of the variables. Thereafter, a multivariate analyses of covariance (MANCOVA) using parent and child gender as independent variables, monthly family income as a covariate, and parent-reported parenting, child-perceived parenting, and child mental health as dependent variables to assess the effect of parental and child gender on parenting and child mental health. Gender differences in parenting were examined because past research $[49,50]$ suggested parenting can be affected by parental as well as child gender. The correlational analyses and the MANCOVA were used to identify possible confounding factors so we can control for their effects in the final hierarchical regression analyses. Paired-sample t-tests were conducted to test for differences between parent-reported parenting and child-perceived parenting. Finally, we conducted hierarchical regression to examine the effects of parent-reported parenting and child-perceived parenting on child mental health after controlling for the effect of family income and child and parental gender.

\section{Results}

\subsection{Descriptive Statistics and Correlations}

Table 2 presents descriptive statistics of the means and standard deviations of the variables, and Table 3 presents the correlation coefficients among all the independent and dependent variables. Because monthly family income was positively correlated with parent-reported authoritative parenting (Spearman's $\rho(649)=0.133, p<0.01)$ as well as child-perceived authoritative parenting $(\rho(648)=0.167$, $p<0.01)$ but negatively correlated with parent-reported authoritarian parenting $(\rho(647)=-0.091$, $p<0.05)$, we decided to control for the effects of monthly family income in subsequent analyses. Parents' marital status did not have significant effects on parents' reported parenting, children's perceived parenting, or children's psychological symptoms (examined using MANOVA); therefore, parents' marital status was not included in the subsequent analyses. 
Table 2. Mean, standard deviations, and range of variables.

\begin{tabular}{cccc}
\hline Measures & Mean & SD & Range \\
\hline Parent-reported Authoritative Parenting & 3.85 & 0.62 & $1-5$ \\
Parent-reported Authoritarian Parenting & 2.02 & 0.55 & $1-5$ \\
Parent-reported Chinese Parenting & 2.94 & 0.45 & $1-5$ \\
Child-perceived Authoritative Parenting & 3.89 & 0.94 & $1-5$ \\
Child-perceived Authoritarian Parenting & 2.21 & 0.95 & $1-5$ \\
Child-perceived Chinese Parenting & 2.57 & 0.89 & $1-5$ \\
\hline Child Psychological Symptoms & & & \\
Anxiety & 0.69 & 0.91 & $0-4$ \\
Hostility & 0.86 & 1.01 & $0-4$ \\
Depression & 0.57 & 0.90 & $0-4$ \\
Interpersonal Sensitivity & 0.78 & 1.02 & $0-4$ \\
Additional Symptoms & 0.50 & 0.88 & $0-4$ \\
BSRS-5 total score & 3.38 & 3.77 & $0-20$ \\
\hline
\end{tabular}

Table 3. Pearson Correlation coefficients among parent-reported parenting, child-perceived parenting, and child psychological symptoms.

\begin{tabular}{|c|c|c|c|c|c|c|}
\hline Variables & 1. & 2. & 3. & 4. & 5. & 6. \\
\hline 1. Authoritative parenting $(\mathrm{P})$ & - & & & & & \\
\hline 2. Authoritarian parenting $(\mathrm{P})$ & $-0.270 * * *$ & - & & & & \\
\hline 3 Chinese parenting $(\mathrm{P})$ & $0.121 * *$ & $0.275^{* * *}$ & - & & & \\
\hline 4. Authoritative parenting (C) & $0.195^{* * *}$ & $-0.125^{* *}$ & 0.024 & - & & \\
\hline 5. Authoritarian parenting $(\mathrm{C})$ & -0.060 & $0.265^{* * *}$ & $0.105 * *$ & $-0.209^{* * *}$ & - & \\
\hline 6. Chinese parenting $(\mathrm{C})$ & -0.036 & $0.117^{* *}$ & $0.141^{* *}$ & $0.090 *$ & $0.330 * * *$ & - \\
\hline 7. Psychological symptoms (C) & -0.002 & $0.121 * *$ & $0.124 * *$ & $-0.234^{* * *}$ & $0.216^{* * *}$ & $0.129 * *$ \\
\hline
\end{tabular}

Note: (P) Parental report, (C) Child report; ${ }^{*} p<0.05,{ }^{* *} p<0.01,{ }^{* * *} p<0.001,2$-tailed.

\subsection{Gender Effect on Parent-Reported Parenting, Child-Perceived Parenting, and Child Mental Health}

The effects of parental and child gender were examined as part of the preliminary analyses. A two-way MANCOVA was conducted to examine the effects of child and parental gender on child-mental health and parent-reported and child-perceived parenting dimensions while controlling for the effects of monthly family income. The MANCOVA revealed significant main effects of parental gender $\left(\mathrm{F}_{(1,615)}=9.223\right.$, Pillai-Bartlett trace $\left.=0.095, p<0.001, \eta^{2}=0.095\right)$ and child gender $\left(\mathrm{F}_{(1,615)}=\right.$ 3.809, Pillai-Bartlett trace $=0.042, p<0.001, \eta^{2}=0.042$ ) on child mental health. Follow-up univariate analyses of variance (ANCOVAs) with Bonferroni corrections were then conducted to examine the effects of monthly family income and parental and child gender on each of the dependent variables. The ANCOVA revealed significant effects for monthly family income (covariate) on parent-reported authoritative parenting $\left(\mathrm{F}_{(1,621)}=13.398, p<0.001\right)$, parent-reported authoritarian parenting $\left(\mathrm{F}_{(1,621)}=\right.$ $4.530, p<0.05)$, and child-perceived authoritative parenting $\left(\mathrm{F}_{(1,621)}=15.077, p<0.01\right)$.

Results also revealed significant univariate effects for child gender on child-perceived authoritative parenting $\left(\mathrm{F}_{(1,621)}=10.660, p<0.001\right)$ and child-perceived authoritarian parenting $\left(\mathrm{F}_{(1,621)}\right.$ $=19.371, p<0.001)$ as well as a significant univariate effect for parental gender on parent-reported authoritative parenting $\left(\mathrm{F}_{(1,621)}=34.842, p<0.001\right)$. There was no significant interaction effect between child and parental gender. Subsequent pairwise comparisons revealed that boys perceived their parents using more authoritarian ( $\mathrm{MD}=0.262, p<0.01$ ) and Chinese-culture specific ( $\mathrm{MD}=0.372, p<0.001$ ) parenting than did girls; and mothers reported higher authoritative parenting $(\mathrm{MD}=0.317, p<0.01$ ) than did fathers. Because child gender and parental gender had significant effects on child-perceived and parent-reported parenting respectively, we controlled for their effects in the subsequent hierarchical regression analyses. 


\subsection{Differences between Parent-Reported and Child-Perceived Parenting}

Paired-sample t-tests were used to examine differences between parent-reported parenting and child-perceived parenting across three parenting dimensions: authoritative, authoritarian, and Chinese parenting. The results revealed that parents reported significantly lower scores on authoritarian parenting than did their children $(t(657)=-5.09, p<0.001)$ but significantly higher scores on Chinese parenting than did their children $(t(656)=10.06, p<0.001$; see Table 4 for summary of the t-tests).

Table 4. Differences between parent-reported and child-perceived parenting across all parenting dimensions.

\begin{tabular}{|c|c|c|c|c|c|c|c|c|}
\hline \multirow{2}{*}{ Parenting Styles } & \multicolumn{2}{|c|}{ Parent-Reported } & \multicolumn{2}{|c|}{ Child-Perceived } & \multirow{2}{*}{$t$} & \multirow{2}{*}{$p$} & \multicolumn{2}{|c|}{$95 \%$ CI } \\
\hline & $\mathbf{M}$ & SD & $\mathbf{M}$ & SD & & & LL & UL \\
\hline Authoritative parenting & 3.85 & 0.62 & 3.89 & 0.94 & -0.922 & 0.357 & -0.114 & 0.041 \\
\hline Authoritarian parenting & 2.01 & 0.55 & 2.20 & 0.95 & $-5.091 * * *$ & 0.000 & -0.265 & 0.118 \\
\hline Chinese parenting & 2.93 & 0.45 & 2.57 & 0.89 & $10.055^{* * *}$ & 0.000 & 0.297 & 0.441 \\
\hline
\end{tabular}

\subsection{Effects of Parent-Reported Parenting and Child-Perceived Parenting on Child Mental Health}

The hierarchical multiple regression analyses (see Table 5) examined whether parent-reported authoritative, authoritarian, and Chinese parenting were significant contributors to children's mental health symptoms, after covariates and the effect of child-perceived parenting were controlled for. Control variables (monthly family income, child gender, and parental gender) were entered into the regression model in the first step (Model 1). Child-perceived parenting variables (i.e., child-perceived authoritative, authoritarian, Chinese parenting) were entered in the second step (Model 2). Parent-reported parenting variables (i.e., parent-reported authoritative, authoritarian, Chinese parenting) were entered as the third step (Model 3).

The results showed that family monthly income, child gender, and parental gender jointly explained $0.4 \%$ of the variance $\left(\mathrm{R}^{2}=0.004, \mathrm{~F}_{(3,621)}=0.834, p=0.475\right)$, and the model was not significant. Adding child-perceived parenting significantly increased the proportion of variance explained $\left(\Delta \mathrm{F}_{(3,618)}=20.624, p<0.001 ; \Delta \mathrm{R}^{2}=0.091\right)$ and adding parent-reported parenting did not significantly increased the proportion of variance explained $\left(\Delta \mathrm{F}_{(3,615)}=1.909, p=0.127 ; \Delta \mathrm{R}^{2}=0.008\right)$.

The regression coefficients indicated that child-perceived authoritative parenting significantly decreased child psychological symptoms scores, whereas child-perceived authoritarian and Chinese parenting significantly increased child psychological symptoms scores even after the effects of child gender, parental gender, and family income were controlled for.

In summary, our findings demonstrated that although parents' and children's reports on parenting were generally consistent (positive but low correlations), parents tended to under-report their use of authoritarian parenting and over-report their use of Chinese-specific parenting compared to their children. As for gender difference, boys perceived their parents using more authoritarian and Chinese-culture specific parenting than did girls; and mothers reported higher authoritative parenting than did fathers. Our findings from the hierarchical regressions showed that children's perception of parenting was a stronger predictor of children's mental health symptoms than parental reports on parenting, urging future research to include children's reports when investigating the effects of parenting on children's mental health outcomes. 
of exposures to violence [59], underscoring the importance of the roles children themselves and their experiences play in mediating the impacts from their parents' parenting.

As for effects of gender, our results showed that mothers reported higher authoritative parenting than fathers did; and boys perceived their parents' parenting to be more authoritarian and Chinese-culture specific than girls did, but parents did not differ in their reported parenting for boys and girls. The parental gender effect was consistent with recent findings that mothers tend to report more authoritative parenting than do fathers $[50,60,61]$. This is also consistent with the traditional Chinese parental roles: 'strict father, warm mother', portraying fathers as more authoritarian, controlling, and strict than mothers, who are portrayed as nurturing and supportive [62]. Although child gender did not affect the parents' self-reported parenting, boys did report higher perceived authoritarian parenting than did girls, which is consistent with previous findings that boys tend to be disciplined more harshly than girls [21,49,63]. Although fathers' and mothers' reports on their own and each other's parenting are generally consistent, they also have a unique influence on child outcomes $[50,61,64,65]$. Therefore, it is advisable in future studies to include parenting reported by both fathers and mothers to examine their joint and unique contribution to child outcomes. Additionally, findings on the gender differences may also be explained by parent-child communication, where adolescent girls tend to be more interdependent of their parents, thus experiencing better quality relationships with their parents than do boys [66,67]. Future studies should incorporate the potential effects of parent-child communication in the examination of parenting and children's wellbeing.

The current study provides unique insights into the relationships between parental and child reports of parenting as well as their effects on children's mental health in the Taiwanese population. However, some limitations need to be acknowledged. First, the current study's design is cross-sectional, making it difficult to determine the direction of influence. It is also possible that children who are depressed tend to interpret their parents' parenting less favorably and more harshly. Future studies with longitudinal designs are needed to further verify such relationships and directions of influence. Second, our parenting measures included only the primary caregiving parent's self-report and child report. Adopting a multi-informant approach, such as including both parents' report and observer's report to study parenting, would provide a better assessment of parenting [49,59]. Moreover, the internal consistency for perceived Chinese parenting subscale was relatively low, and thus our findings will need to be validated by future research. Due to constraints on time and resources, we could not explore the diverse components of Chinese parenting in more detail, which surely warrants more attention in future research. Third, child psychological symptoms were only measured by children's self-report. Future studies should include report from different sources, such as parents and teachers, to provide more information. Finally, the current study only included participants from Taiwan, limiting the generalizability of the findings. Even within Chinese ethnic groups, the sub-cultures across different Chinese societies (such as Mainland China, Hong Kong, Taiwan, Macau) could be considerably distinct [52]. Future research including non-Chinese samples as well as Chinese populations from various societies would further our understanding of the interaction between parenting and child mental health in different social-cultural contexts.

\section{Conclusions}

The current study provided insights into the relationships between parental and child reports of parenting as well as their effects on children's mental health, adding the Chinese cultural perspectives to further our understanding of parenting and child mental health outcome. Our findings also remind scholars and clinicians as well as policy makers on the importance of taking children's perspectives into account when examining their mental health outcome, as they may have more direct influence on their mental health outcomes. For instance, multiple sources could be considered when assessing children and adolescents' adjustment, but the voices from the young people should be especially valued. In the Chinese socio-cultural context, parents tend to be especially involved in their children's education. However, the parents' overprotection may have undesirable effects on children's mental 
health. Thus, education professionals should be especially aware of such a delicate balance between parental involvement and respecting children's own voice. In addition, given the links between parental approval of physical punishment and child physical abuse [68,69], the Taiwanese children, especially boys, perhaps are at a higher risk of physical abuse, and this risk might be perpetuated by the promotion of parental authority in Chinese culture. The undesirable effect of authoritarian and Chinese parenting on children's mental health warrants more future investigations with a Chinese population, underscoring the importance of looking at human development from a holistic and culturally-sensitive perspective.

Author Contributions: Conceptualization, C.-Y.H.; methodology, Y.-P.H. and A.C.-T.S., and H.-S.W., J.-Y.F., H.-L.H., and C.-Y.H.; formal analysis, C.-Y.H.; writing —original draft preparation, C.-Y.H.; writing—review and editing, Y.-P.H. and A.C.-T.S.; funding acquisition, J.Y.F.

Funding: This research was funded by National Taiwan University Children and Family Research Center.

Acknowledgments: The authors are grateful to the participation of the parents and children in this study.

Conflicts of Interest: The authors declare no conflict of interest. The funders had no role in the design of the study; in the collection, analyses, or interpretation of data; in the writing of the manuscript; or in the decision to publish the results.

\section{References}

1. DeHart, T.; Pelham, B.W.; Tennen, H. What lies beneath: Parenting style and implicit self-esteem. J. Exp. Soc. Psychol. 2006, 42, 1-17. [CrossRef]

2. Morris, A.S.; Silk, J.S.; Steinberg, L.; Myers, S.S.; Robinson, L.R. The role of the family context in the development of emotion regulation. Soc. Dev. 2007, 16, 361-388. [CrossRef] [PubMed]

3. Fletcher, A.C.; Walls, J.K.; Cook, E.C.; Madison, K.J.; Bridges, T.H. Parenting Style as a Moderator of Associations Between Maternal Disciplinary Strategies and Child Well-Being. J. Fam. Issues 2008, 29, 1724-1744. [CrossRef]

4. Maccoby, E.E.; Martin, J.A. Socialization in the context of family: Parent-child interaction. In Handbook of Child Psychology: Socialization, Personality and Social Development; Hetherington, E.M., Ed.; Wiley: New York, NY, USA, 1983; Volume 4, pp. 1-101.

5. Baumrind, D. Effects of authoritative parental control on child behavior. Child Dev. 1966, 37, 887-907. [CrossRef]

6. Akcinar, B.; Baydar, N. Parental control is not unconditionally detrimental for externalizing behaviors in early childhood. Int. J. Behav. Dev. 2014, 38, 118-127. [CrossRef]

7. Möller, E.L.; Nikolić, M.; Majdandžić, M.; Bögels, S.M. Associations between maternal and paternal parenting behaviors, anxiety and its precursors in early childhood: A meta-analysis. Clin. Psychol. Rev. 2016, 45, 17-33. [CrossRef] [PubMed]

8. García, O.F.; Serra, E.; Zacarés, J.J.; García, F. Parenting styles and short-and long-term socialization outcomes: A study among Spanish adolescents and older adults. Psychosoc. Interv. 2018, 27, 153-161. [CrossRef]

9. Moreno-Ruiz, D.; Estévez, E.; Jiménez, T.; Murgui, S. Parenting style and reactive and proactive adolescent violence: Evidence from Spain. Int. J. Environ. Res. Public Health 2018, 15, 2634. [CrossRef]

10. Pinquart, M. Associations of Parenting Dimensions and Styles with Internalizing Symptoms in Children and Adolescents: A Meta-Analysis. Marriage Fam. Rev. 2017, 53, 613-640. [CrossRef]

11. Pinquart, M. Associations of Parenting Dimensions and Styles with Externalizing Problems of Children and Adolescents: An Updated Meta-Analysis. Dev. Psychol. 2017, 53, 873-932. [CrossRef] [PubMed]

12. Bornstein, M.H.; Cote, L.R.; Venuti, P. Parenting beliefs and behaviors in northern and southern groups of Italian mothers of young infants. J. Fam. Psychol. 2001, 15, 663-675. [CrossRef] [PubMed]

13. Smetana, J.G. Current research on parenting styles, dimensions, and beliefs. Curr. Opin. Psychol. 2017, 15, 19-25. [CrossRef] [PubMed]

14. Wu, P.; Robinson, C.C.; Yang, C.; Hart, C.H.; Olsen, S.F.; Porter, C.L.; Jin, S.; Wo, J.; Wu, X. Similarities and differences in mothers' parenting of preschoolers in China and the United States. Int. J. Behav. Dev. 2002, 26, 481-491. [CrossRef] 
15. Deater-Deckard, K.; Lansford, J.E.; Malone, P.S.; Alampay, L.P.; Sorbring, E.; Bacchini, D.; Bombi, A.S.; Bornstein, M.H.; Chang, L.; Di Giunta, L.; et al. The association between parental warmth and control in thirteen cultural groups. J. Fam. Psychol. 2011, 25, 790-794. [CrossRef] [PubMed]

16. Chen, X.; Liu, M.; Li, D. Parental warmth, control, and indulgence and their relations to adjustment in Chinese children: A longitudinal study. J. Fam. Psychol. 2000, 14, 401-419. [CrossRef] [PubMed]

17. Cheah, C.S.L.; Leung, C.Y.Y.; Tahseen, M.; Schultz, D. Authoritative parenting among immigrant Chinese mothers of preschoolers. J. Fam. Psychol. 2009, 23, 311-320. [CrossRef]

18. Wang, Q.; Pomerantz, E.M.; Chen, H. The role or parents' control in early adolescents' psychological functioning: A longitudinal investigation in the United States and China. Child Dev. 2007, 78, 1592-1610. [CrossRef] [PubMed]

19. Nelson, D.A.; Hart, C.H.; Yang, C.; Olsen, J.A.; Jin, S. Aversive Parenting in China: Associations with Child Physical and Relational Aggression. Child Dev. 2006, 77, 554-572. [CrossRef]

20. Fung, J.J.; Lau, A.S. Punitive discipline and child behavior problems in Chinese American immigrant families: The moderating effects of indigenous child-rearing ideologies. Int. J. Behav. Dev. 2009, 33, 520-530. [CrossRef]

21. Chang, L.; Schwartz, D.; Dodge, K.A.; McBride-Chang, C. Harsh parenting in relation to child emotion regulation and aggression. J. Fam. Psychol. 2003, 17, 598-606. [CrossRef]

22. Kim, S.Y.; Wang, Y.; Orozco-Lapray, D.; Shen, Y.; Murtuza, M. Does "tiger parenting" exist? Parenting profiles of Chinese Americans and adolescent developmental outcomes. Asian Am. J. Psychol. 2013, 4, 7-18. [CrossRef] [PubMed]

23. Liu, Y.; Merritt, D.H. Examining the association between parenting and childhood depression among Chinese children and adolescents: A systematic literature review. Child. Youth Serv. Rev. 2018, 88, 136-332. [CrossRef]

24. Chen, X.; Liu, M.; Li, D.; Chen, G.; Chen, H.; Wang, L. Maternal authoritative and authoritarian attitudes and mother-child interactions and relationships in urban China. Int. J. Behav. Dev. 2000, 22, 119-126. [CrossRef]

25. Quoss, B.; Zhao, W. Parenting styles and children's satisfaction with parenting in China and the United States. J. Comp. Fam. Stud. 1995, 26, 265-280.

26. Chao, R.K. Beyond parental control and authoritarian parenting style: Understanding Chinese parenting through the cultural notion of training. Child Dev. 1994, 65, 1111-1119. [CrossRef]

27. Huang, C.Y.; Lamb, M.E. Acculturation and Parenting in First-Generation Chinese Immigrants in the United Kingdom. J. Cross-Cult. Psychol. 2015, 46, 150-167. [CrossRef]

28. Chao, R.K. Extending research on the consequences of parenting style for Chinese Americans and European Americans. Child Dev. 2001, 72, 1832-1843. [CrossRef] [PubMed]

29. Ho, D.Y.F. Chinese patterns of socialization: A critical review. In The Psychology of the Chinese People; Bond, M.H., Ed.; Oxford University Press: Hong Kong, China, 2008; p. 1037.

30. Lin, C.; Fu, V. A comparison of child-rearing practices among Chinese, immigrant Chinese, and CaucasianAmerican parents. Child Dev. 1990, 61, 429-433. [CrossRef]

31. Lieber, E.; Fung, H.; Leung, P.W.-L. Chinese child-rearing beliefs: Key dimensions and contributions to the development of culture-appropriate assessment. Asian J. Soc. Psychol. 2006, 9, 140-147. [CrossRef]

32. Chen, X.; Hastings, P.D.; Rubin, K.H.; Chen, H.; Cen, G.; Stewart, S.L. Child-rearing attitudes and behavioural inhibition in Chinese and Canadian toddlers: A cross-cultural study. Dev. Psychol. 1998, 34, 1-10. [CrossRef]

33. Huang, C.Y. Chinese Parenting and Children's Compliance to Adults: A Cross-Cultural Comparative Study. Ph.D. Thesis, University of Cambridge, Cambridge, UK, 2013.

34. Huang, C.Y.; Cheah, C.S.L.; Lamb, M.E.; Zhou, N. Associations Between Parenting Styles and Perceived Child Effortful Control Within Chinese Families in the United States, the United Kingdom, and Taiwan. J. Cross-Cult. Psychol. 2017, 48, 795-812. [CrossRef] [PubMed]

35. Barber, B.K.; Harmon, E.L. Violating the self: Parental psychological control of children and adolescents. In Intrusive Parenting: How Psychological Control Affects Children and Adolescents; Barber, B.K., Ed.; American Psychological Association: Washington, DC, USA, 2002; pp. 15-52. [CrossRef]

36. Barry, C.T.; Frick, P.J.; Grafeman, S.J. Child versus parent reports of parenting practices: Implications for the conceptualization of child behavioral and emotional problems. Assessment 2008, 15, 294-303. [CrossRef] [PubMed]

37. Korelitz, K.E.; Garber, J. Congruence of Parents' and Children's Perceptions of Parenting: A Meta-Analysis. J. Youth Adolesc. 2016, 45, 1973-1995. [CrossRef] 
38. Locke, L.M.; Prinz, R.J. Measurement of parental discipline and nurturance. Clin. Psychol. Rev. 2002, 22, 895-929. [CrossRef]

39. Zaslow, M.J.; Weinfield, N.S.; Gallagher, M.; Hair, E.C.; Ogawa, J.R.; Egeland, B.; Tabors, P.O.; De Temple, J.M. Longitudinal prediction of child outcomes from differing measures of parenting in a low-income sample. Dev. Psychol. 2006, 42, 27-37. [CrossRef] [PubMed]

40. Martínez, I.; Garcia, F.; Fuentes, M.C.; Veiga, F.; Garcia, O.F.; Rodrigues, Y.; Cruise, E.; Serra, E. Researching Parental Socialization Styles across Three Cultural Contexts: Scale ESPA29 Bi-Dimensional Validity in Spain, Portugal, and Brazil. Int. J. Environ. Res. Public Health 2019, 16, 197. [CrossRef] [PubMed]

41. Tabak, I.; Zawadzka, D. The importance of positive parenting in predicting adolescent mental health. J. Fam. Stud. 2017, 23, 1-18. [CrossRef]

42. Frampton, K.L.; Jenkins, J.M.; Dunn, J. Within-family differences in internalizing behaviors: The role of children's perspectives of the mother-child relationship. J. Abnorm. Child Psychol. 2010, 38, 557-568. [CrossRef] [PubMed]

43. De Los Reyes, A.; Ehrlich, K.B.; Swan, A.J.; Luo, T.J.; Van Wie, M.; Pabo'n, S.C. An experimental test of whether informants can report about child and family behavior based on settings of behavioral expression. J. Child Fam. Stud. 2013, 22, 177-191. [CrossRef]

44. De Los Reyes, A.; Augenstein, T.M.; Wang, M.; Thomas, S.A.; Drabick, D.A.; Burgers, D.E.; Rabinowitz, J. The validity of the multi-informant approach to assessing child and adolescent mental health. Psychol. Bull. 2015, 141, 858-900. [CrossRef]

45. Wu, C.; Chao, R.K. Intergenerational cultural dissonance in parent and adolescent relationships among Chinese and European Americans. Dev. Psychol. 2011, 47, 493-508. [CrossRef] [PubMed]

46. Robinson, C.C.; Mandelco, B.; Olsen, S.F.; Hart, C.H. The parenting styles and dimensions questionnaire (PSQD). In Handbook of Family Measurement Techniques; Perlmutter, B.F., Touliatos, J., Holden, G.W., Eds.; SAGE: Thousand Oaks, CA, USA, 2001; Volume 3, pp. 319-321.

47. Chen, H.C.; Wu, C.H.; Lee, Y.J.; Liao, S.C.; Lee, M.B. Validity of the five-item Brief Symptom Rating Scale among subjects admitted for general health screening. J. Formos. Med. Assoc. 2005, 104, 824-829. [PubMed]

48. Lu, I.C.; Jean, M.C.Y.; Lei, S.M.; Cheng, H.H.; Wang, J.D. BSRS-5 (5-item Brief Symptom Rating Scale) scores affect every aspect of quality of life measured by WHOQOL-BREF in healthy workers. Qual. Life Res. 2011, 20, 1469-1475. [CrossRef]

49. McKee, L.; Roland, E.; Coffelt, N.; Olson, A.L.; Forehand, R.; Massari, C.; Jones, D.; Gaffney, C.A.; Zens, M.S. Harsh discipline and child problem behaviors: The roles of positive parenting and gender. J. Fam. Violence 2007, 22, 187-196. [CrossRef]

50. Rinaldi, C.M.; Howe, N. Mothers' and fathers' parenting styles and associations with toddlers' externalizing, internalizing, and adaptive behaviors. Early Child. Res. Q. 2012, 27, 266-273. [CrossRef]

51. Bögels, S.M.; van Oosten, A.; Muris, P.; Smulders, D. Familial correlates of social anxiety in children and adolescents. Behav. Res. Ther. 2001, 39, 273-287. [CrossRef]

52. Caster, J.B.; Inderbitzen, H.M.; Hope, D. Relationship between youth and parent perceptions of family environment and social anxiety. J. Anxiety Disord. 1999, 13, 237-251. [CrossRef]

53. Barber, B.K. Intrusive Parenting: How Psychological Control Affects Children and Adolescents; American Psychological Association: Washington, DC, USA, 2002.

54. Fung, H. Becoming a moral child: The socialization of shame among young Chinese children. Ethos 1999, 27, 180-209. [CrossRef]

55. Rose, J.; Roman, N.; Mwaba, K.; Ismail, K. The relationship between parenting and internalizing behaviours of children: A systematic review. Early Child Dev. Care 2018, 188, 1468-1486. [CrossRef]

56. Bögels, S.M.; Van Melick, M. The relationship between child-report, parent self-report, and partner report of perceived parental rearing behaviors and anxiety in children and parents. Personal. Individ. Differ. 2004, 37, 1583-1596. [CrossRef]

57. Taylor, A.; Wilson, C.; Slater, A.; Mohr, P. Parent-and child-reported parenting. Associations with child weight-related outcomes. Appetite 2011, 57, 700-706. [CrossRef] [PubMed]

58. Huang, C.Y.; Shen, A.C.T.; Hsieh, Y.P.; Feng, J.Y.; Wei, H.S.; Hwa, H.L.; Feng, J.Y. Cultural Perspectives on Parenting, Emotional Intelligence and Mental Health in Taiwanese Children. Int. J. Emot. Educ. 2017, 9, 4-16.

59. Moed, A.; Gershoff, E.T.; Bringewatt, E.H. Violence exposure as a mediator between parenting and adolescent mental health. Child Psychiatry Hum. Dev. 2017, 48, 235-247. [CrossRef] 
60. Chuang, S.S.; Su, Y. Do we see eye to eye? Chinese mothers' and fathers' parenting beliefs and values for toddlers in Canada and China. J. Fam. Psychol. 2009, 23, 331-341. [CrossRef]

61. Gamble, W.C.; Ramakumar, S.; Diaz, A. Maternal and paternal similarities and differences in parenting: An examination of Mexican-American parents of young children. Early Child. Res. Q. 2007, 22, 72-88. [CrossRef]

62. Wilson, R.W. The Moral State: A Study of the Political Socialization of Chinese and American Children; Free Press: New York, NY, USA, 1974.

63. Sorbring, E.; Rödholm-Funnemark, M.; Palmérus, K. Boys' and girls' perceptions of parental discipline in transgression situations. Infant Child Dev. 2003, 12, 53-69. [CrossRef]

64. Cabrera, N.J.; Tamis-LeMonda, C.S.; Bradley, R.H.; Hofferth, S.; Lamb, M.E. Fatherhood in the twenty-first century. Child Dev. 2000, 71, 127-136. [CrossRef]

65. Luo, R.; Tamis-Le Monda, C.S.; Song, L. Chinese parents' goals and practices in early childhood. Early Child. Res. Q. 2013, 28, 843-857. [CrossRef]

66. De Goede, I.H.; Branje, S.J.; Meeus, W.H. Developmental changes in adolescents' perceptions of relationships with their parents. J. Youth Adolesc. 2009, 38, 75-88. [CrossRef] [PubMed]

67. Keijsers, L.; Poulin, F. Developmental changes in parent-child communication throughout adolescence. Dev. Psychol. 2013, 49, 2301-2308. [CrossRef]

68. Maker, A.H.; Shah, P.V.; Agha, Z. Child physical abuse: Prevalence, characteristics, predictors, and beliefs about parent-child violence in South Asian, Middle Eastern, East Asian, and Latina Women in the United States. J. Interpers. Violence 2005, 20, 1406-1428. [CrossRef] [PubMed]

69. Park, M.S. The factors of child physical abuse in Korean immigrant families. Child Abuse Negl. 2001, 25, 945-958. [CrossRef]

(C) 2019 by the authors. Licensee MDPI, Basel, Switzerland. This article is an open access article distributed under the terms and conditions of the Creative Commons Attribution (CC BY) license (http:/ / creativecommons.org/licenses/by/4.0/). 